new growths. The book would be improved if classifications of cervical polypi and the causes of postmenopausal bleeding were included, whilst the different manifestations of phlebitis might well appear in the chapter devoted to pelvic infections.

Some of the diagrams are poor and those on pages 83,93 (b) and 127 should be redrawn. Faulty proofreading is shown by numerous spelling mistakes (including perenium on page $I$ and perinium on page 27), whilst there is a serious transposition of lines on page 140. In spite of these defects, the book well serves its purpose as a useful aid to revision.

\section{Contributions to Obstetrics and Gynæcology}

V. N. SHIRodkar, M.D.(Bom.), F.R.c.s., F.A.c.s. Pp. vii + I 59, illustrated. Edinburgh and London: E. \& S. Livingstone Ltd. 1960. 37s. $6 d$.

It is always a pleasure to read the author's account of his own operation and the description of Shirodkar's operation for the treatment of habitual abortion in the second trimester of pregnancy makes this book something of a classic.

Professor Shirodkar's experience over 35 years of specialist practice makes up the rest of the book. Some of the other operations he describes are more debatable.

The photographs and line drawings are many and excellent and this, no doubt, accounts for the comparatively high price.

\section{Peptic Ulceration}

A Symposium for Surgeons. C. A. Wells, F.R.C.s.; J. KYLE, M.CH., F.R.C.S. Pp. xi +259 , illustrated. Edinburgh and London: E. \& S. Livingstone Ltd. 1960. 42s.

Although the cause of peptic ulceration remains unknown, a considerable amount of significant information about various aspects of the condition and its many complications is constantly being discovered. Much of this new information is of importance to the physician and surgeon in their management of patients with a peptic ulcer. In this monograph Professor Wells and Mr. Kyle, assisted by a team of experts most of whom are connected with Liverpool School of Medicine, set out to describe for surgeons these recent developments, a basic knowledge of the condition and its complications being assumed. The book ends with translations of some of the classical, early German contributions to the subject.

In general the book succeeds admirably in its object, and can be recommended to surgeons as a lucid, comprehensive review of all the important new work in this field of surgery. As a general comment it seems a pity that the book is confined to the surgical aspects of the subject. The treatment of this condition demands close collaboration between physician and surgeon, and their respective roles in the management of the various problems presented by peptic ulceration are so intermingled that it seems unrealistic to discuss one without the other. As would be expected from these authors and publishers, the book is admirably produced and there is an excellent subject and author index, though it is a surprise in a book of this sort to find no reference in the index to the Zollinger-Ellison syndrome.

The book opens with an admirable chapter on the epidemiology of peptic ulcer, which should be read by all those who treat this condition. There follow chapters on ætiology, clinical features, operative management, early and late complications, and recurrent ulceration. As is perhaps inevitable in this sort of book the standard is a little uneven. The chapters dealing with the ætiology of peptic ulcer, its surgical management, and the delayed complications and sequelæ of partial gastrectomy are excellent. In general, the remainder constitute useful 으 modern reviews of their aspects of the problem, though the metabolic lesion in pyloric stenosis is rather super-尺 ficially considered. With these minor qualifications, the $c$. book can be strongly recommended to postgraduate students, and all those concerned with this branch of $\bar{\omega}$ surgery will find in this commendably brief volume much of value and stimulus to them in their day-to-day management of patients with this important and common condition.

Fundamental Techniques of Plastic Surgery and $\underset{\mathscr{\infty}}{\varrho}$
their Surgical Application

I. A. McGregor; C. F. W. Illingworth. Pp. $\overrightarrow{0}$ viii +244 , illustrated. Edinburgh and London: E. \& S. Livingstone Ltd. 1959.30 .

The first part of this work provides a reasoned account of the plastic surgeon's approach to the closure of wounds, and describes in detail the techniques of 3 . suturing and skin grafting, as well as the provision of $\omega$ full skin replacement. The second part elaborates the $-V$ application of the foregoing to a wide variety of con- $\vec{N}$ ditions, including skin avulsions and neoplasms, eyelid $\omega$ reconstruction, hand injuries and pressure sores. Much sound information is readably presented and clearly $\mathrm{O}$ illustrated with photographs and line drawings.

Students of plastic surgery may not agree with all the views expressed, but will find the work stimulating and $c$ informative. Those for whom this specialty is still mysterious will find enlightenment in its pages. One hopes the book may not be misinterpreted as an easy guide to plastic surgery, a mistake which could have $\overrightarrow{0}$ been rendered less likely if the author had been mofe of specific abnut how far he considered the general surge should venture.

\section{Clinical Disorders of the Pulmonary Circulation}

Editors: R. DALEY, M.A., M.D.(CAMB.), F.R.C.P.; J. F. GoODWIN, M.D., F.R.C.P.; R. E. STEINER, 응 M.D., N.U.I., M.R.C.P., D.M.R., F.F.R. Pp. xii + 364. with I 33 illustrations. London: J. \& A. Churchill $=$ Ltd. I960. 75 s.

This important book is written by a team of nine, most of whom are at the Postgraduate Medical School of London or have been connected with it. This is both understandable and appropriate when one remembers 7 the great contributions which stem from the pioneer 3 work of McMichael and Sharpey-Schafer. The book will interest all who are concerned with heart and lung disease, and parts of it could be recommended to students.

The subject is covered in 14 chapters, each of which has been written by an individual, and the approach is 0 not standardized. One sympathizes with the editors in their task of handling such a team, all writing within a $\frac{7}{2}$ restricted field; and one can agree that there is merit in allowing the contributors 'free expression of views $\mathrm{N}$ and presentation'. Nevertheless, stricter editorial $\sigma$ policy would improve subsequent editions. The book $\mathrm{N}$ approximates more to a comprehensive account of the pulmonary circulation in health and disease than its title $\omega$ implies, and the contributors might have produced $\sigma$ accounts with less overlap and fewer omissions had such an approach been made explicit and imposed by the editors. Specific examples of unrewarding overlap $\mathbb{D}$ include the anatomical details in the chapters on? anatomy and radiology, and the several variations on a $T$ common theme of the classification of pulmonary ${ }^{\circ}$ hypertension (the theme itself coming in for criticism 